\title{
Descriptive Sensory Characteristics of Meat from Grower Rabbits Fed on Fermented Ground Mature Prosopis juliflora Pods Based-diets
}

\author{
Jane Atieno Odero-Waitituh ${ }^{1,2, *}$, Anthony Macharia King'ori ${ }^{2}$, Mary Kivali Ambula ${ }^{2}$, \\ Joseph Wafula Matofari ${ }^{3}$, Stephen Odera Onyango ${ }^{3}$, Robert Mwasigwa ${ }^{2}$ \\ ${ }^{1}$ School of Agriculture, Natural Resources and Environmental Studies, Rongo University, Rongo, Kenya \\ ${ }^{2}$ Department of Animal Sciences, Egerton University, Egerton, Kenya \\ ${ }^{3}$ Dairy and Food Science and Technology Department, Egerton University, Egerton, Kenya
}

Email address:

atiwaitts@gmail.com (J. A. Odero-Waitituh), akingori@egerton.ac.ke (A. M. King'ori), m.ambula@egerton.ac.ke (M. K. Ambula), jmatofari@egerton.ac.ke (J. W. Matofari), stephenwill12@gmail.com (S. O. Onyango), mwbobby247@gmail.com (R. Mwasigwa)

${ }^{*}$ Corresponding author

\section{To cite this article:}

Jane Atieno Odero-Waitituh, Anthony Macharia King'ori, Mary Kivali Ambula, Joseph Wafula Matofari, Stephen Odera Onyango, Robert Mwasigwa. Descriptive Sensory Characteristics of Meat from Grower Rabbits Fed on Fermented Ground Mature Prosopis juliflora Pods Based-diets. World Journal of Food Science and Technology. Vol. 5, No. 2, 2021, pp. 19-24. doi: 10.11648/j.wjfst.20210502.11

Received: April 6, 2021; Accepted: April 19, 2021; Published: April 29, 2021

\begin{abstract}
The effect of inclusion of graded levels of fermented ground mature Prosopis juliflora pods (FGMPP) replacing maize grain in grower rabbits' diets on sensory attributes was investigated. Thigh muscles were obtained from 12-week-old rabbits fed on five diets comprising: control (formulated standard grower diet), 15\% UGMPP, 30\% UGMPP, 15\% FGMPP and $30 \%$ FGMPP replacing maize in standard grower diets. Deep-frozen meats from the rabbits were thawed and boiled in different aluminium pots, cut into small pieces of about $2 \mathrm{~cm}^{3}$ placed in ceramic plates and presented to 12 panellists. Questionnaires were used for sensory attribute profiling. Data were analysed using SPSS Statistics 25.0.0 and the general linear model (GLM) of Statistical Analysis Systems (SAS) softwares for Principal Component Analysis (PCA) and analysis of variance (ANOVA) respectively. Tukey's range procedure was used to separate means at $(\mathrm{p}<0.05)$ significance. The PCA indicated that grittiness, particles, oiliness, colour, salty taste and oily taste contributed greatest to the observed variability. According to ANOVA, there was no treatment effect $(\mathrm{p}>0.05)$ in overall rating, appearance, flavour and colour of the meat. However, there was treatment effect $(p<0.05)$ on beefy taste, tenderness, salty taste and grittiness. The study concluded that $30 \%$ maize grain in the diets of grower rabbits can be replaced with FGMPP as it did not affect consumer preference of the meat.
\end{abstract}

Keywords: Carcass, Fermentation, Mature Prosopis juliflora Pods, Grower Rabbits, Sensory Evaluation

\section{Introduction}

The steady increase in human population in African countries has resulted in sub division of available land for human settlement. This has caused a decrease in land available for food production while the demand for food continues to rise $[1,2]$. The economic reality for these countries is to reduce food importation by increasing production of livestock species that are easy to rear and costeffective, given the available land and resources [1]. Among the available options, rabbit production and rabbit meat consumption has been identified as a suitable sustainable alternative animal protein source [3]. Rearing rabbits is attractive in terms of their feed consumption which is low and diverse, ease of rearing and home consumption; a rabbit can be eaten in one meal, presenting no conservation problems [4]. Rabbit production and meat consumption is therefore, a feasible option to meet the demands of consumers and ensure animal protein supply thereby preventing malnutrition [3]. However, rabbit performance is low. This is due to fluctuation in feed quality and prices as a result of the use of cereals and agricultural by-products as feed ingredients. They are mostly rain-fed and also food for 
man resulting in inadequate supply especially during periods of scarcity [5].

There have been efforts to explore and use nonconventional feed ingredients such as mature Prosopis pods with positive results on livestock growth performance [6]. There was no significant $(\mathrm{p}>0.05)$ effect on consumer preference of meat from indigenous chicken fed mature Prosopis juliflora pods [7]. Also, toxicological tests done on rats by Wamburu et al. [8] reported that mature Prosopis pods exhibited $\mathrm{LD}_{50}$ that exceeded $5000 \mathrm{mg} / \mathrm{kg}$ and was therefore safe for use by humans and animals with a degree of safety and tolerance. However, reports by Odero-Waitituh et al. [9] indicated that high tannins $(8 \%)$ and crude fibre $(\mathrm{CF})(17 \%)$ in the pods interfered with livestock performance with recommendations that treatment could reduce the concentrations of tannins and $\mathrm{CF}$ and therefore improved livestock performance could be realised. Several studies have reported improvement in nutritional value and reduction in anti-nutritional compounds. According to Yusuf et al. [10] and Odero-Waitituh et al. [11], spontaneous fermentation of decorticated Prosopis africana seed meal and mature Prosopis juliflora pods enhanced crude protein (CP) and essential amino acids while $\mathrm{CF}$ was reduced resulting in improvement of broiler and rabbit growths were respectively.

Generally, sensory attributes of meat are influenced by animal genetics and prevailing animal environment, with feed factors forming the larger part of the environmental effect [12]. Proper animal nutrition management not only affects livestock health, welfare and productivity but also the quality and safety of animal products. It also safeguards consumers against diseases and poor health. It is therefore important to observe and practice all animal management aspects and practices that will ensure that product quality and safety is not compromised [13]. Studies indicate that consumer food choices for meat and meat products are influenced by the understanding of the effects of the meat on their health, descriptive sensory attributes of the products and reasonable prices [14]. Evaluation of sensory attributes of meat allow producers to develop more precise knowledge about consumer attitudes and perceptions related to food products and ensure that the animal product produced is acceptable to consumers $[15,16]$. This study evaluated descriptive sensory characteristics of meat from grower rabbits as affected by feeding fermented ground mature Prosopis pods-based diets.

\section{Materials and Methods}

\subsection{Study Site}

The feeding experiment was conducted at the rabbit unit, Tatton Agriculture Park, Egerton University, Kenya. The descriptive sensory evaluation was carried out at the sensory room, Guildford Dairy Institute, Dairy, Food Science and Technology Department of Egerton University. Egerton is located at latitude $0^{\circ} 23^{\prime} \mathrm{S}$ and longitude $35^{\circ} 57^{\prime} \mathrm{E}$ with an altitude of $2,238 \mathrm{~m}$ above sea level. It has a mean daily temperature of $21^{\circ} \mathrm{C}$. There is a bimodal rainfall pattern (March to May and June to September) with a mean annual rainfall of $900-1,020 \mathrm{~mm}$ [17].

\subsection{Dietary Treatments, Experimental Design and Meat Sample Collection}

The rabbits were fed five diets that were formulated to grower rabbit requirements [18]. They comprised; 30\% UGMPP; 15\% UGMPP; 30\% FGMPP; 15\% FGMPP and control. In a randomized complete block design (RCBD), five dietary treatments were randomly allocated to 60 grower rabbits (30 bucks and 30 does) with four replicates per treatment. Each experimental unit comprised 3 rabbits. On the $42^{\text {nd }}$ day of the experimental period, one rabbit from each experimental unit was selected randomly, numbered, and fasted overnight with ad-libitum provision of drinking water before slaughter. Slaughtering was done according to the welfare law [19]. The rabbits were slaughtered following the cervical dislocation method, bled then skinned and eviscerated [20]. Good manufacturing practices were observed at all times. The meat was frozen for 2 weeks before analysis.

\subsection{Training and Selection of Panellists}

Selection of panellists was done by administration of prescreening questionnaires to 20 candidates. The pre-screening questionnaires included questions about availability, food habits, flavour, texture and aroma of different products and questions about allergenicity to meat-based products. This was done to select candidates who were verbal about sensory properties and able to participate in the rabbit meat sensory evaluation. During the orientation sessions, the panel agreed on the attributes to use for evaluation, evaluated several meat samples from the rabbits offered (control/reference diet, $30 \%$ FGMPP and 30\% UGMPP inclusion diets) and rated their intensities (agreed upon by consensus by the panellists). The samples were used as warm-up samples and were provided to the panellists to enable them to identify the intensities and develop the sensory lexicon during the tasting sessions. From the pre-screening questionnaires, 12 of the candidates were selected according to the procedure by Meilgaard et al. [21] as verbal concerning sensory properties. They were then trained on both qualitative and quantitative meat discrimination. During the training, the following sensory lexicon with 15 descriptors was developed (Table 1).

\subsection{Sensory Evaluation}

Frozen meat samples, in different containers, were thawed using running tap water for 6 hours. This was followed by sample preparation by boiling for 40 minutes in different aluminium pots labelled with random three-digit numbers. The boiled meats were then cut into small pieces of about 2 $\mathrm{cm}^{3}$ using a kitchen knife. Ceramic plates divided into five portions (according to the assigned codes) were used to present the cut meat samples to the panellists. Stainless steel fork and knife were also availed to every panellist. Water was 
provided for cleansing and rinsing the palate between appearance, aroma and flavour using the sensory descriptors samples. The panellists evaluated the meat samples for developed during training.

Table 1. Sensory lexicon developed during training of the selected panellists.

\begin{tabular}{lll}
\hline Term & Definition & Rating scale \\
\hline Colour & Actual colour of the sample & $1=$ White; $7=$ Brown \\
Denseness & Compactness of the cross-section & $1=$ Less compact; 7=Very compact \\
Oiliness & Presence of visible oil & $1=$ None; 7=High \\
Chicken aroma & Aromatic associated with cooked chicken & $1=$ None; 7=High \\
Salty taste & Taste associated with iodized salt & $1=$ None; 7=High \\
Chicken flavour & Flavour associated with cooked chicken & $1=$ None; 7=High \\
Beefy flavour & Flavour associated with cooked beef & $1=$ None; 7=High \\
Tenderness & Ease of chewing & $1=$ Tough; 7=Tender \\
Juiciness & Moisture released by the product in the mouth as a result of chewing & $1=$ None; 7=High \\
Rubbery & Degree to which sample returns to original shape after some deformation & $1=$ None; 7=High \\
Grittiness & Amount of small, hard particles between teeth during chew & $1=$ None; 7=High \\
Oily residual & Degree to which mouth feels oily after swallowing & $1=$ None; 7=High \\
Particle residuals & The amount of particles left in mouth after swallowing & $1=$ None; 7=Many \\
Teeth adhesion & Mouth residues that remain stuck on teeth & $1=$ None; 7=High \\
Metallic after-taste & Metallic flavour similar to the one produced by iron (II) sulphate & $1=$ None; 7=High \\
\hline
\end{tabular}

\subsection{Statistical Analysis}

Using SPSS Statistics 25.0.0 software, data were subjected to normality and homogeneity of variance test. Principal component analysis (PCA) was performed on descriptive sensory attributes to identify attributes that explained the greatest amount of the observed variabilities. Data were then subjected to analysis of variance (ANOVA) using the general linear model (GLM) of Statistical Analysis Systems (SAS, 9.1.3) computer package. The differences among treatment means were determined using the Tukey's range test. Probability values of $(\mathrm{p}<0.05)$ were considered significant.

\section{Results}

Table 2. Illustrates results from principal component analysis
(PCA). Principal component (PC) 1 demonstrated that chicken flavour, chicken aroma and oily aftertaste followed the same trend and were negatively correlated to residual particles, grittiness and teeth adhesion. Principal component 2 showed oiliness, juiciness and tenderness were similar but negatively correlated with rubbery taste and teeth adhesion, metallic taste, grittiness and chicken flavour were similar but negatively correlated to denseness in PC 3. Principal component 4 showed the same trend on colour, salty taste and rubbery having a positive correlation. Principal component 5 demonstrated a negative correlation between oiliness and salty taste. Grittiness, particles, oiliness, colour, salty taste and oily taste contributed greatest to the observed variabilities according to the PCA. Mean rankings of the descriptive sensory attributes are presented in Table 3. Only salty taste, beefy flavour, grittiness and tenderness were significantly affected by feeding.

Table 2. Principal components with factor loadings of descriptive sensory properties of meat from grower rabbits fed FGMPP and UGMPP-based diets.

\begin{tabular}{|c|c|c|c|c|c|c|}
\hline \multirow{2}{*}{ Attribute } & \multicolumn{6}{|c|}{ Principal Components } \\
\hline & PC1 & PC2 & PC3 & PC4 & PC5 & PC6 \\
\hline Colour & -.008 & .360 & -.277 & .599 & .315 & -.221 \\
\hline Denseness & .297 & -.268 & -.423 & .255 & .291 & .320 \\
\hline Oiliness & .024 & .649 & .051 & .212 & .538 & -.277 \\
\hline Chicken aroma & -.673 & -.343 & .298 & .120 & -.123 & -.325 \\
\hline Salty taste & -.029 & .365 & .144 & .469 & -.610 & -.191 \\
\hline Chicken & -.637 & -.225 & .431 & .264 & .067 & -.015 \\
\hline Tenderness & -.379 & .479 & -.112 & -.249 & .195 & .347 \\
\hline Juiciness & -.117 & .535 & .312 & -.019 & -.199 & .315 \\
\hline Rubbery & .299 & -.458 & -.047 & .574 & -.071 & .359 \\
\hline Grittiness & .537 & .035 & .597 & .057 & .282 & -.170 \\
\hline oily & -.520 & .333 & .326 & .071 & .056 & .432 \\
\hline Particles & .793 & .007 & .381 & -.015 & -.030 & -.044 \\
\hline Teeth adhesion & .515 & .010 & .487 & -.292 & .054 & .089 \\
\hline Eigenvalues & 2.875 & 2.022 & 1.745 & 1.451 & 1.251 & 1.037 \\
\hline Variance explained (\%) & 19.168 & 13.477 & 11.633 & 9.675 & 8.34 & 6.913 \\
\hline
\end{tabular}

Extraction Method: Principal Component Analysis

Rotation Method: Varimax with Kaiser Normalization

KMO 0.503

Bartlett's Test: Chi square value 196.229; $<<0.0001$ 
Table 3. Effect of feeding grower rabbits FGMPP and UGMPP-based diets on sensory attributes of meat.

\begin{tabular}{|c|c|c|c|c|c|c|c|}
\hline Attribute & $30 \%$ UGMPP & $15 \%$ UGMPP & $30 \%$ FGMPP & $15 \%$ FGMPP & Control & SEM & p-value \\
\hline \multicolumn{8}{|l|}{ Overall rating } \\
\hline Overall & 4.42 & 5.5 & 5.5 & 4.91 & 5.08 & 0.35 & 0.18 \\
\hline Appearance & 5.42 & 5.25 & 5.67 & 4.42 & 5.33 & 0.41 & 0.27 \\
\hline Flavour & 5.67 & 5.58 & 5.25 & 4.02 & 4.83 & 0.39 & 0.45 \\
\hline Texture & 4.67 & 5.67 & 5.58 & 5.5 & 4.75 & 0.37 & 0.17 \\
\hline \multicolumn{8}{|l|}{ Appearance } \\
\hline Colour & 4.33 & 3.83 & 4.0 & 4.58 & 4.5 & 0.44 & 0.71 \\
\hline Oiliness & 4.83 & 3.0 & 4.08 & 4.58 & 4.25 & 0.47 & 0.08 \\
\hline Denseness & 4.17 & 3.92 & 4.25 & 4.33 & 4.67 & 0.51 & 0.88 \\
\hline \multicolumn{8}{|l|}{ Flavour } \\
\hline Salty taste & $2.67^{\mathrm{a}}$ & $2.42^{\mathrm{a}}$ & $2.58^{\mathrm{a}}$ & $4.83^{\mathrm{b}}$ & $3.92^{\mathrm{ab}}$ & 0.45 & 0.0008 \\
\hline Oily & 4.0 & 3.08 & 2.5 & 3.3 & 3.58 & 0.47 & 0.23 \\
\hline Chicken & 4.5 & 4.17 & 4.58 & 4.33 & 4.17 & 0.43 & 0.94 \\
\hline Beefy & $3.33^{\mathrm{a}}$ & $1.83^{\mathrm{ac}}$ & $2.58^{\mathrm{a}}$ & $3.9^{\mathrm{ab}}$ & $1.75^{\mathrm{ac}}$ & 0.44 & 0.003 \\
\hline \multicolumn{8}{|l|}{ Texture } \\
\hline Particles & 3.08 & 3.17 & 4.5 & 3.75 & 3.91 & 0.46 & 0.19 \\
\hline Grittiness & $3.67^{\mathrm{a}}$ & $1.83^{\mathrm{b}}$ & $4.67^{\mathrm{ad}}$ & $2.58^{\mathrm{ab}}$ & $4.17^{\mathrm{a}}$ & 0.45 & 0.0002 \\
\hline Tenderness & $5.58^{\mathrm{a}}$ & $4.58^{\mathrm{ab}}$ & $3.67^{\mathrm{b}}$ & $4.33^{\mathrm{ab}}$ & $5.41^{\mathrm{a}}$ & 0.47 & 0.04 \\
\hline Juiciness & 4.25 & 3.5 & 3.5 & 4.17 & 5.0 & 0.5 & 0.19 \\
\hline Rubbery & 3.17 & 3.75 & 4.58 & 3.67 & 4.0 & 0.51 & 0.4 \\
\hline \multicolumn{8}{|l|}{ Aroma } \\
\hline Chicken & 4.58 & 5.5 & 4.83 & 4.58 & 4.42 & 0.42 & 0.4 \\
\hline \multicolumn{8}{|l|}{ Residual } \\
\hline Teeth adhesion & 3.42 & 3.5 & 4.0 & 3.67 & 3.58 & 0.47 & 0.91 \\
\hline Metallic aftertaste & 3.0 & 2.83 & 4.5 & 3.25 & 3.0 & 0.44 & 0.07 \\
\hline
\end{tabular}

$\mathrm{SEM}=$ standard error of means; $\mathrm{a}$, b, c, $d=$ means in the same row with different superscripts are significantly different $(\mathrm{P}<0.05)$; Trt $1=30 \%$ UGMPP (unfermented mature Prosopis pods); Trt 2=15\% UGMPP; Trt 3=30\% FGMPP (fermented ground mature Prosopis pods); UGMPP; Trt 4=15\% FGMPP; Trt $5=$ control.

\section{Discussions}

In PC 1, the inverse relationship between chicken aroma, chicken taste and oiliness to beefy taste, grittiness, particles and teeth adhesion is an indication of the attributes that constitute beef and chicken meats. Chicken meat has different but specific attributes from beef that are negatively correlated. In PC 2, the positive correlation between juiciness, tenderness and oiliness is an indication of their contribution to the overall rating of the meat, and therefore their positive contribution to meat quality. The negative correlation (inverse relationship) of these attributes with the rubbery attribute is an indication of poor meat quality. These results indicate the overall relationship between beef and chicken meats with regards to quality where chicken meats are considered of higher quality by consumers. Similar results were reported by Trout et al. [22] and Ruiz-Carrascal et al. [23] when relationships between texture, appearance, presence of moisture and intramuscular fat content of meat were studied. There was a direct relationship between these attributes, meat quality and meat preference as reported by consumers. In this study, feeding FGMPP or UGMPP did not affect the relationships of the attributes that represent consumer preference and quality. Similar results were reported by Wanjohi et al. [7] when indigenous chicken were fed ground mature Prosopis pods based-diets.

Out of the nineteen attributes evaluated, only four were significant according to ANOVA, Table 3. This substantiates several similar studies that highlighted that meat sensory attributes are less influenced by diet, when indigenous chicken were fed Prosopis pods [7]; when broilers were fed soaked Prosopis seeds [24]; when chicken were fed enzymetreated and untreated Prosopis pods [25]; when pigs were fed fermented food waste [26] and when broiler chicken were fed fermented rapeseed meal [27]. Generally, large amounts of changes in the diet composition are needed to cause minute changes in sensory attributes [28]. According to Tasić et al. [29], grittiness is an inverse indicator of meat quality. The similarity in the grittiness of meat of the rabbits fed the control diet and 30\% FGMPP inclusion diet is an indication of similar meat quality. In the present study, it was shown that feeding UGMPP at $30 \%$ did not cause significant differences in grittiness. However, when fed at low levels (15\%), whether fermented or not, ground mature Prosopis juliflora pods reduced the grittiness of the rabbits' meat. Thus, $15 \%$ UGMPP can be used to improve meat quality as grittiness inversely affects meat quality [29]. In this study, meat from the rabbits offered treatment with $30 \%$ FGMPP had lower $(p<0.05)$ salt content. This is desirable to the consumers. Daily salt intake in humans is high due to diets consisting of processed foods with high salt content. This predisposes people to cardiovascular diseases like high blood pressure. Low salt diets are important in reducing blood pressure of hypertensive individuals [30]. In this study, the meat from the rabbits fed on diets with 30\% FGMPP inclusion would be ideal for preventing and reducing cardiovascular diseases in humans due to the low salt content [31]. Although analysis by PCA reported beefy taste and tenderness with a low contribution to the observed variabilities, they were significant $(\mathrm{p}<0.05)$ in ANOVA 
analysis. They are important descriptive sensory attributes that indicate consumer preference for meats and therefore their purchasing-decision process [32]. Tenderness is an important attribute to the older population compared to younger people and unlike juiciness, it rarely determined consumer buying decisions [26].

According to Guerrero et al. [33], meat quality is affected by several factors like diet, production system, age with meat from goats reared with milk replacers as opposed to dams' milk exhibiting differences in sensory attributes [34]. In this study, age and production system was the same across all treatments. The only effect investigated on descriptive sensory attributes was therefore the diets. According to Guerrero et al. [35], some of the dietary factors that determine differences in quantitative and qualitative properties of meat are physical properties, chemical properties, use of additives and composition of the diets. Many of the nutrients in meat are also involved in flavour formation. There is therefore a linear relationship between the nutritional aspect of meat and its flavour [36]. In this study, similar sensory attributes in the overall ratings exhibited by meat in all the treatments is an indication that all the diets provided adequate nutrients to allow for normal metabolism in muscular tissues. According to Font-i-Furnols and Guerrero [37], the overall rating of meat as appearance, flavour and texture were more important in consumer buying decisions of meat. In this study, differences in these individual descriptive sensory attributes did not affect the overall rating of the meat from rabbits in all the treatments.

\section{Conclusions}

Based on the results of this study, it is concluded that up to $30 \%$ of maize grain in grower rabbits' diets can be replaced with fermented ground mature Prosopis pods. The meat had a lower salty taste and was similar to the control in the overall rating. This inclusion did not affect descriptive sensory characteristics. The prevailing price of maize as compared to the price of FGMPP will determine the cost-benefit of the replacement as these prices are subject to seasonal fluctuations.

\section{Acknowledgements}

This research was funded by Centre of Excellence in Agriculture and Agribusiness Management (CESAAM), Egerton University, Egerton, Kenya. Funding number: (IDA CREDIT NO 579-KE). The authors wish to thank the Centre.

\section{References}

[1] Cheeke, P. R. (1986). Potentials of rabbit production in tropical and subtropical agricultural systems. Journal of Animal Science 63 (5), 1581-1586.

[2] Jayne, T. B., Muyanga, M., Yeboah, F. K., Ayala. W. \& Lulama, T. (2017). Mega trends driving Agricultural Transformation in Africa; Challenges and opportunities. Public address, Egerton University, Kenya.
[3] Mutsami, C., Mburu, J., Wanyoike, M. \& Ochieng, S. (2019). The rabbit value chain in Kenya: A framework for food policy and research. Livestock Research for Rural Development, Volume 31, Article \#71.

[4] Butcher, C., Bryant, M. J., Machin, D. H., Owen, E., \& Owen, J. E. (1981). The Effect of Metabolizable Energy Concentration on Performance and Digestibility in Growing Rabbits. Tropical Animal Production 6 (2), 93-100.

[5] Smith, J., Sones, K., Grace, D., MacMillan, S., Tarawali, S., \& Herrero, M. (2013). Beyond milk, meat, and eggs: Role of livestock in food and nutrition security. Animal Frontiers 3 (1), 6-13.

[6] Wanjohi, D. M., King'ori, A. M., Wachira, A. M., \& Guliye, A. Y. (2017). Effect of replacing complete grower diet with ground Prosopis juliflora pods on performance of improved indigenous chicken in Kenya. Livestock Research for Rural Development Volume 29, Article, 157.

[7] Wanjohi, D. M., King'ori, A. M., Wachira, A. M., Guliye, A. Y., \& Ngoda, P. N. (2017). Sensory attributes and quality of meat in improved indigenous chicken fed on Prosopis juliflora pods in Kenya. African Journal of Food Science and Technology 8 (8), 132-137.

[8] Wamburu, R. W., Kareru, P. G., Mbaria, J. M., Nyaga, G., \& Rechab, S. O. (2015). Spectrometric detection of organic compounds and toxicity of ethanolic leaves extracts of Prosopis juliflora. Chemistry Material Research 7, 21-25.

[9] Odero-Waitituh, J. A. (2015). Evaluation of inclusion levels of milled mature pods of Prosopis juliflora (Mathenge) in broiler finisher diets. (Master's Thesis, Egerton University, Njoro. Kenya).

[10] Yusuf, N. D., Ogah, D. M., Hassan, D. I., Musa, M. M., \& Doma, U. D. (2008). Effect of decorticated fermented Prosopis seed meal (Prosopis africana) on growth performance of broiler chicken. International Journal of Poultry Science 7 (11), 1054-1057.

[11] Odero-Waitituh, J. A., Kingori, A. M., \& Ambula, M. K. (2020). Bio-economic Implications of Feeding Fermented Ground Mature Prosopis juliflora Pods to Grower Rabbits. Journal of Economic Impact 2 (2), 43-49.

[12] Shahidi, F., Rubin, L. J., D'Souza, L. A., Teranishi, R., \& Buttery, R. G. (1986). Meat flavor volatiles: A review of the composition, techniques of analysis, and sensory evaluation. Critical Reviews in Food Science \& Nutrition 24 (2), 141-243.

[13] Food and Agriculture Organization (FAO). (2014). Importance of accurate feed analysis in enhancing safety and quality of food, increasing productivity and welfare of the animal and conserving the environment. http://www.fao.org/ag/againfo/home/en/news_archive/AGA_i n_action/2014_Importance_of_accurate_feed_analysis.html.

[14] Mermelstein, N. H. (2002). A look into the future of food science \& technology. Food Technology-Champaign then Chicago 56 (1), 46-55.

[15] Sidel, J. L., \& Stone, H. (1993). The role of sensory evaluation in the food industry. Food Quality and Preference 4 (1-2), 65-73.

[16] Akinboye, O E., Nwangburuka, E. C., Tayo, G. O., Adeyemi, O. A., Oyekale, K. O., Olumide, M. D., Chioma, G. O., \& Akinboye, O. O. (2018). Sensory Evaluation of Meat of Broiler Poultry Birds Fed with Tomato-supplemented Feed. American Scientific Research Journal for Engineering, Technology, and Sciences 47 (1), 145-150. 
[17] Egerton University Meteorological Station. (2019). Climatic data. Egerton University, Njoro Campus, Kenya.

[18] Deblas, C. \& Mateos, G. G. (2010). Feed formulation. In: Deblas, C., Wiseman, J. (Eds), Nutrition of the rabbits (pp. 222). CAB International. UK.

[19] Lafuente, R., \& López, M. (2014). Effect of electrical and mechanical stunning on bleeding, instrumental properties and sensory meat quality in rabbits. Meat science 98 (2), 247-254.

[20] Martin, J. E., McKeegan, D. E., Sparrey, J., \& Sandilands, V. (2016). Comparison of novel mechanical cervical dislocation and a modified captive bolt for on-farm killing of poultry on behavioural reflex responses and anatomical pathology. Animal Welfare, 25 (2) 227-241.

[21] Meilgaard, M., Civille, G. V. \& Carr, B. T. (2000). Sensory Evaluation Techniques, Chapter 5 and 12. Descriptive Analysis Techniques 4.

[22] Trout, E. S., Hunt, N. C., Johnson, D. E., Claus, J. R., Kastner, C. L., Kropf, D. H., \& Stroda, S. (1992). Chemical, physical and sensory characterization of ground beef containing 5 to $30 \%$ fat. Journal of Food Sciences 57 (1), 25-29.

[23] Ruiz-Carrascal, J., Ventanas, J., Cava, R., Andrés, A. I., \& Garcia, C. (2000). Texture and appearance of dry cured ham as affected by fat content and fatty acid composition. Food Research International 33 (2), 91-95.

[24] Ausol, Z. E., \& Mukhtar, A. M. (2011). Effect of feeding broiler chicks on graded levels of soaked Prosopis seeds. Australian Journal of Basic and Applied Sciences 5 (7), 45-48.

[25] Al-Marzooqi, W., Al-Kharousi, K., Kadim, I. T., Mahgoub, O., Zekri, S., Al-Maqbaly, R., \& Al-Busaidi, M. (2015). Effects of feeding Prosopis juliflora pods with and without exogenous enzyme on performance, meat quality and health of broiler chickens. International Journal of Poultry Science 14 (2), 76.

[26] Aaslyng, M. D., Oksama, M., Olsen, E. V., Bejerholm, C., Baltzer, M., Andersen, G.,... \& Gabrielsen, G. (2007). The impact of sensory quality of pork on consumer preference. Meat Science 76 (1), 61-73.

[27] Ashayerizadeh, A., Dastar, B., Shargh, M. S., Mahoonak, A. S. \& Zerehdaran, S. (2018). Effects of feeding fermented rapeseed meal on growth performance, gastrointestinal microflora population, blood metabolites, meat quality, and lipid metabolism in broiler chickens. Livestock Science 216, 183-190.

[28] Barbut, S. (2015). Structure and Muscle Physiology. Chapter 3. In: The Science of Poultry Meat and Processing. University of Guelph. Guelph, Ontario, Canada. ISBN 978-0-88955-626-3.

[29] Tasić, A., Kureljušić, J., Nešić, K., Rokvić, N., Vićentijević, M., Radović, M., \& Pisinov, B. (2017). Determination of calcium content in mechanically separated meat. In IOP Conference Series: Earth and Environmental Science, (Vol. 85, No. 1, p. 012056). IOP Publishing.

[30] He, F. J., Markandu, N. D., \& MacGregor, G. A. (2001). Importance of the renin system for determining blood pressure fall with acute salt restriction in hypertensive and normotensive whites. Hypertension 38 (3), 321-325.

[31] Jiménez-Colmenero, F., Carballo, J., \& Cofrades, S. (2001). Healthier meat and meat products: their role as functional foods. Meat Science 59 (1), 5-13.

[32] Savell, J. W., Crss, H. R., Francis, J. J., Wise, J. W., Hale, D. S., Wilkes, D. L., \& Smith, G. C. (1989). National consumer retail beef study: Interaction of trim level, price and grade on consumer acceptance of beef steaks and roasts. Journal of Food Quality 12 (4), 251-274.

[33] Guerrero, A., Del Mar Campo, M., Olleta, J. L. \& Sañudo, C. (2018). Carcass and meat quality in goat. Goat Science 12, 267-286.

[34] Argüello, A., Castro, N., Capote, J., \& Solomon, M. (2005). Effects of diet and live weight at slaughter on kid meat quality. Meat Science 70 (1), 173-179.

[35] Guerrero, A., Velandia Valero, M., Campo, M. M., \& Sañudo, C. (2013). Some factors that affect ruminant meat quality: from the farm to the fork. Review. Acta Scientiarum. Animal Sciences 35 (4), 335-347.

[36] Farmer, L. J. (1994). The role of nutrients in meat flavour formation. Proceedings of the Nutrition Society 53 (2), 327333.

[37] Font-i-Furnols, M., \& Guerrero, L. (2014). Consumer preference, behavior and perception about meat and meat products: An overview. Meat science 98 (3), 361-371. 